\title{
Platformization Practices of Health Information Systems: A Case of National eHealth Platforms
}

\author{
Duong Dang \\ University of Vaasa \\ duong.dang@uwasa.fi
}

\author{
Samuli Pekkola \\ Tampere University \\ samuli.pekkola@tuni.fi
}

\author{
Tero Vartiainen \\ University of Vaasa \\ tero.vartiainen@uwasa.fi
}

\author{
Son Pham \\ Vietnam National University \\ sonph@hubt.edu.vn
}

\begin{abstract}
Using electronic health (eHealth) platforms is an approach for reaching more people to get services-for example during pandemics or disasters. eHealth platforms help reduce costs and improve the general quality of healthcare. However, establishing eHealth platforms at the national level is challenging due to legal, privacy, and financial constraints. Furthermore, studies on the national eHealth platform in the public sector are scarce. This motivated us to study and understand the process of implementing a public national eHealth platform. We use a qualitative case study as a research approach and the theory of practice and concept of site as lenses to examine the platformization practices of three national-level eHealth platforms. We contribute to the literature by identifying key features of site-shifting in eHealth and describing the practices and features of involved practitioners and the site regarding the process of establishing the platform. Our findings benefit practitioners, as the platformization phases can be seen as lessons when establishing a national eHealth platform. Additionally, the three approaches discussed in this study could be seen as a guide to creating national eHealth platforms.
\end{abstract}

\section{Introduction}

The digital transformation of the healthcare sector has been studied in past decades [1,2,3]. Governments have used digital platforms as a means to deliver their services. These platforms have played major roles in the digital age [4]. For example, digital platforms enable the building of a powerful innovation ecosystem, support social interactions, and act as engines for growth. This has increased common interest in national eHealth platforms. In fact, many countries have already launched or are currently in the process of establishing national platforms for eHealth services [5]. Yet, establishing nationwide eHealth platforms is not easy as several challenges in governance-with numerous legal issues, difficulties in operations, or impacts on economics - have been identified [6, 7, 8]. For example, Paparova and Aanestad [9] discussed eHealth platforms being siloed and spread across the entire information infrastructure. They proposed that researchers focus on how different eHealth platforms can be integrated across information infrastructures to improve healthcare service delivery.

In this study, we tackle this issue by answering the following research question: How are national eHealth platforms established? Particularly, we examine the platformization practices of national eHealth platforms, which refer to the practice of consolidating existing information systems (IS) with digital technology to design, develop, and use digital platforms. However, our focus on national eHealth platforms has been overlooked in the literature despite its potential benefits [10].

We draw on the theory of practice [11] and the concept of site [12], where the practitioners perform and engage in platformization practices. In essence, we focus on the day-to-day activities of the practitioners who shape, refine, and materialize ideas through their activities. To understand these practices, we conducted a case study of three eHealth platforms. By examining the interrelation of practitioners and their platformization practices, we can see how the site (e.g., a type of context) of platformization practices shifts (e.g., changes in the platformization practices due to the changes in the dynamic relationships of human beings, artifacts, and other organisms) over time.

Our findings show that the driving force to create a shift in the platformization site comes from technologies, legislations, and practitioners' awareness of improvement or adaptation to the site's environments. The findings indicate that while technology plays an important role, the coordinator and the government's involvement are imperative in establishing national eHealth platforms. The coordinators help integrate and harmonize existing practices to improve healthcare service delivery, while the government resolves policy-and legislation-related 
problems (e.g., regarding the user's privacy, patient's data, and standards). In that sense, the success of the platforms depends on their ability to harmonize the existing practices and relationships among involved practitioners. This study shows that platform owners can be replaced by non-focal actors, which refers to practitioners who do not own or cannot establish personal infrastructures or platforms at the time [13] because of changes in the site's environments. This indicates that to survive and succeed in business, both non-focal actors and platform owners need to establish a dynamic bi-directional relationship.

We contribute to the literature by introducing new characteristics of the platformization practice (namely, technical, sociotechnical, and organizational practices). Interestingly, each practice has its key practitioners, and the roles of technology and infrastructure differ in each phase. For example, open Internet platforms (Google apps, Facebook APIs) can offer enormous power to developers and user organizations, but they play a limited role in the technical practice of platformization. We argue that the process of development and integration into platforms is reactive, where most development activities are done against the changes in the capabilities of the infrastructure or to provide a fit between the infrastructure and the business need [14]. However, this process is also influenced by the relationships between the platformization practices and their material arrangements.

The remainder of this study is structured as follows. First, the background section is presented. Second, we describe the methods and case settings. Third, the findings section presents the illustrative insights. Finally, we present the discussions and conclusions.

\section{Background}

\subsection{Digital Platforms}

Digital platforms are considered a multidisciplinary research topic covering engineering, economics, and organizational perspectives $[15,16]$. This variety has resulted in their numerous definitions [6, 17, 18]. For example, technical studies of digital platforms focus on their technological and digital characteristics (e.g., layered architecture and modularity) [19], while IS researchers adopt a broader focus on their sociotechnical dimensions (e.g., the impact of digital platforms on organizational structures or culture) [20]. These different definitions however share several characteristics: the platforms are technologically mediated, enable interaction among platform users, and allow platform users to conduct defined tasks [20]. In this study, a platform refers to the technical components (software and hardware) and associated organizational processes and standards [20], p.127. Platformization is the process of consolidating existing IS with digital technology to design, develop, and use digital platforms.

There is a growing number of IS studies on platforms [20, 21]. Most studies focus on private sector platforms, driven by technology and market logics [4, 22]. The literature also discusses organizational platforms (e.g., intranets, firm's forum) and open Internet platforms (e.g., Facebook, Instagram). However, a few studies have discussed platforms for public services [23] and challenges with public platforms, such as legacy, privacy, and inclusiveness [8, 10]. For example, legacy health information systems (HIS) are often brittle, slow, and non-extensible, and they face a challenge in balancing between privacy (e.g., patient protection) and interoperability. The challenges of inclusiveness relate to the involvement of as many actors as possible, such as reaching out to all citizens by accommodating their different needs. These issues have negative impacts on the establishment of a platform.

\subsection{Platform in Healthcare}

HIS are not immune to digital transformation. Digital platforms help organizations move from standalone HIS to platforms despite the large-scale infrastructure and numerous stakeholders across different professions, sites and locations, hospitals, and regions.

The literature discusses different aspects of HIS and eHealth platforms. For example, eight topics are often discussed in the HIS literature. They include the integrated management of information technology (IT) in healthcare, medical images, electronic medical records, the development of portable devices, mobile devices in healthcare, access to eHealth, telemedicine, and the privacy of medical data [3]. From the perspective of HIS implementation, the characteristics include operational efficiency by healthcare providers, patient-centered approaches, organizational factors and managerial implications, workforce practices, and socio-economic aspects. These categories improve the service providers' operational efficiencies through technological implementation [24].

Unfortunately, most studies have focused on the organizational level and environment and are driven by market logic. Conversely, the national level and public domain are relatively underexplored, with little empirical research [3, 10, 24], although many countries advocate national frameworks and platforms regarding technical advancements or policies [25, 26]. This is because a national eHealth framework may improve the quality and accessibility of healthcare and reduce its cost [8]. Paparova and Aanestad [9] discussed three 
focal points of eHealth platforms: platform governance and boundary resources as governance mechanisms, platform ecosystems as a means of co-innovation, and platform architecture emphasizing technical innovations in the underlying architecture.

Implementing digital platforms causes organizational changes $[1,2]$. These changes can be highly challenging due to their high privacy and security requirements, fragmented organizations and infrastructure, and politicized environment driven by self-assertive professionalism [23, 27]. This study unravels the process of establishing national eHealth platforms. In other words, we study the platformization of HIS to understand how it becomes a national eHealth platform.

\subsection{Theoretical Lens}

We adopt the theory of practice [11] as our theoretical lens. IS scholars have used it to study digital transformation $[28,29,30]$ since it allowed researchers to focus on mundane managerial activities from micro or macro levels of analyses [31,32]. It also examines the relationship between micro-processes and macrooutcomes [33]. Practices are organized human activities and refer to "embodied, materially mediated arrays of human activities centrally organized around shared practical understanding" [11], p.11. The practice literature uses the same notion of site that we use to examine how an eHealth platform is built in practice. The concept of site has been used in the IS literature [12, $29,34]$. Site refers to a context or set of material arrangements and practices that are in a dynamic relationship with each other [12], while material arrangements mean "set-ups of material objects. Whenever someone acts and therewith carries on a practice, she does so in a setting that is composed of material entities. The material arrangements amid which humans carry on embrace four types of entities: human beings, artifacts, other organisms, and things." [12] p472.

We use the concept of site $[12,34]$ to study the dynamic relationship between material arrangements and eHealth platformization practice (Figure 1).

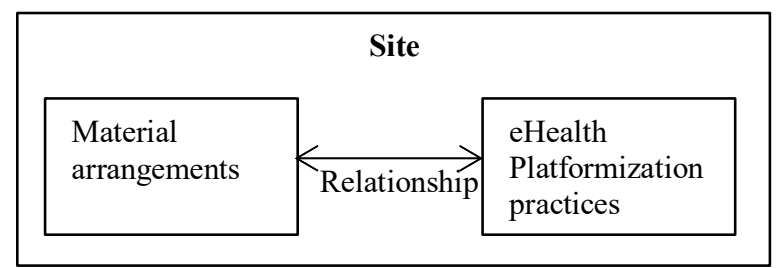

Figure 1. The site framework for the study

\section{Cases and Research Methods}

\subsection{Healthcare Systems and Public eHealth Platform in the Case Setting}

Our empirical setting is a single case study in Vietnamese healthcare. The healthcare system has four layers: the central government (e.g., the Ministry of Health), local governments, counties, and municipalities. There are about 14,000 health facilities (HFs) in the country. Most of them are publicly owned but partly funded by the government. The central government plays a major role, as it operates hierarchically, with responsibilities shared between the central (the Ministry) and local governments, counties, and municipalities. Thus, health services can be universally accessed. However, selected healthcare services are influenced by political bodies across political systems.

The three eHealth nationwide platforms included in our study are the electronic medical records platform (MRP), medical facilities information systems (MCIS) management platform, and telehealth. Particularly, the MRP is responsible for medical patients' information. It is connected to the national social insurance database and allows any authorized party to monitor the patients, including the patients themselves. The MRP manages about 98 million records. The MCIS platform handles the management of HFs. For example, there are more than 11 IS for an HF, and the MCIS platform helps with their consolidation and replacement. It is used in all HFs across the country. Telehealth connects more than 1,500 HFs (by the end of 2020) that support long-distance clinical healthcare, patient and professional healthrelated education, public health, and health administration.

\subsection{Methods}

This study used a single case study approach [35, 36]. Particularly, we analyzed three nationwide platforms that have been implemented for eHealth in Vietnam. This case was selected for several reasons. First, we had the opportunity to conduct interviews with different stakeholders. Second, we had access to secondary data. Finally, nationwide eHealth platforms are significant in improving the quality and accessibility of healthcare with affordable costs. They may thus have the potential to impact the entire healthcare system in the country.

3.2.1 Data Collection. We conducted 45 semistructured interviews with open-ended questions with the platforms' owners (e.g., Electronic Health Administration under the Ministry of Health), the 
platforms' users (e.g., HFs, patients), the platforms' partners (e.g., developers, services providers, advisers), and other agencies (e.g., the authority of IT applications). Our main data collection took place between January 2020 and January 2021. The interviews lasted between 26 and $113 \mathrm{~min}$, with an average length of $39.6 \mathrm{~min}$. Follow-up questions were asked via telecommunications software, emails, and informal dialogues. Furthermore, secondary data was used to support our data collection and data analysis process. They include internal documents, project documents, meeting memos, press releases, conference materials, and online materials.

3.2.2 Data Analysis. We first moved all data (interview transcripts and secondary data) to NVIVO software to assist in the data analysis. Data analysis was conducted in Vietnamese and then selectively translated to English when writing this study. Data analysis was guided by the site lens. The process of iterative data analysis is described as follows.

First, we started the data analysis by writing a case study write-up [37]. This helped us gain an overview of the case timeline and refine the data collection process. The key points from the interviews, documents, and notes were summarized, which helped reduce the length of the pages into manageable data and identify key facts and points. For example, "first telehealth was established in 2006" and "there were approximately 11 HIS in an HF before 2017."

Second, the iterative analysis identified material arrangements and practices following the theory of practice and the concept of site from the interview data. This helped to identify the relevant practitioners (e.g., HFs, providers, patients), the activities of platformization practices (e.g., top-down setup of HF infrastructures from the national level to lower levels), and the site-shifting phenomenon (e.g., changes in the relationship and the roles of practitioners).

Third, we identified the main phases of the platformization process of eHealth HIS. Fourth, we built a periodization of the phenomenon (e.g., the site transition related to practice arrangements and their changes). Particularly, we devised three phases following how the changes happened. Each phase appeared differently in each platform, but there was a common approach to practicing platformization. Figures 2-4 later illustrate the site of the eHealth HIS platformization practices, where the practitioners and the interrelationships between the practitioners and practices are shown, as well as the site of the platformization practices at different periods. Three themes, technical, sociotechnical, and organizational practices, were identifiable.

Finally, we built the storyline based on the three phases. During this process, we cross-checked and constantly compared our findings to ensure all key points and events were recorded and presented. The results of the data analysis and our interpretation are shown in the subsequent sections.

\section{Case Findings}

In this section, we present each phase of the platformization practice and provide descriptions of the case through material arrangements, practices, and their dynamic relationships. Table 1 summarizes our three practices, which will be illustrated in each phase.

Table 1. Practices of platformization, their features, and practitioners

\begin{tabular}{|c|c|c|}
\hline $\begin{array}{l}\text { Practices of } \\
\text { Platformization }\end{array}$ & Features & Practitioners \\
\hline $\begin{array}{l}\text { Technical } \\
\text { practice } \\
\text { (before 2013) }\end{array}$ & $\begin{array}{l}\text { The platform is } \\
\text { technically oriented. } \\
\text { HFs' IT and technical } \\
\text { departments are } \\
\text { responsible for most } \\
\text { tasks in setting up a } \\
\text { platform. } \\
\text { involvement of other } \\
\text { practitioners is very } \\
\text { limited. }\end{array}$ & $\begin{array}{l}\text { HF } \\
\text { (Platform } \\
\text { owner), } \\
\text { provider, } \\
\text { patient }\end{array}$ \\
\hline $\begin{array}{l}\text { Sociotechnical } \\
\text { practice (2013- } \\
2017)\end{array}$ & $\begin{array}{l}\text { The technical } \\
\text { infrastructure is } \\
\text { associated with } \\
\text { processes and standards. } \\
\text { The new practitioner is } \\
\text { involved in practices } \\
\text { (e.g., government) and } \\
\text { co-responsible for the } \\
\text { platform development. }\end{array}$ & $\begin{array}{l}\text { HF } \\
\text { (Platform } \\
\text { owner), } \\
\text { provider, } \\
\text { patient, } \\
\text { government }\end{array}$ \\
\hline $\begin{array}{l}\text { Organizational } \\
\text { practice (2018- } \\
2020)\end{array}$ & $\begin{array}{l}\text { The government } \\
\text { becomes a coordinator } \\
\text { that connects all } \\
\text { practitioners } \\
\text { promotes } \\
\text { interoperability among } \\
\text { different platforms. The } \\
\text { providers become } \\
\text { platform co-owners with } \\
\text { the government. HFs } \\
\text { function as platform } \\
\text { users only. }\end{array}$ & $\begin{array}{l}\text { HF, } \\
\text { provider } \\
\text { (platform } \\
\text { co-owner), } \\
\text { patients, } \\
\text { government } \\
\text { (platform } \\
\text { co-owner) }\end{array}$ \\
\hline
\end{tabular}




\section{Phase 1. Platformization as a Technical Practice}

We illustrate the platformization practice before 2013 (Figure 2), where the arrows represent the interactions between the practitioners in the site.

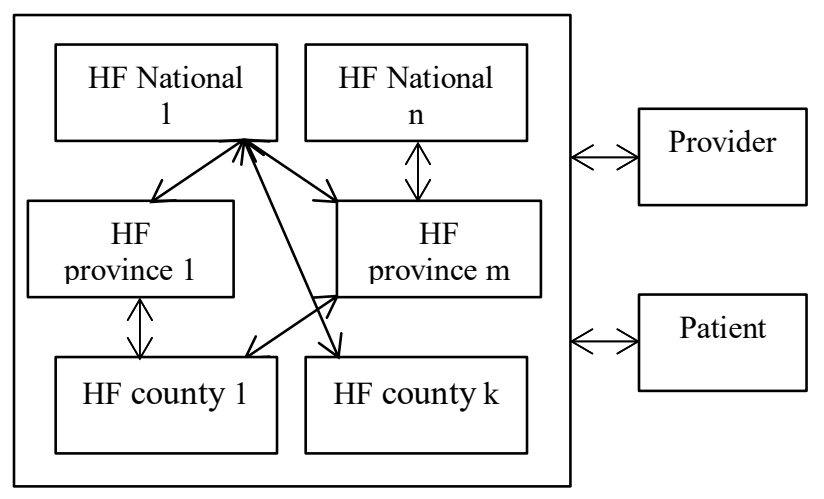

Figure 2. Platformization practice patterns (before 2013); key players: national HF

A platform was initiated by an $\mathrm{HF}$ at the national level. This HF functioned as a practitioner. They coordinated their work with other practitioners (e.g., other HFs, providers, and patients) and demonstrated the limitations of the HFs. For example, in the case of the telehealth platform, the first national telehealth system was established in 2006. It was a simple system that connected one national hospital (at the VD hospital) to four other HFs in the provinces and counties. At that time, establishing a surgery at an HF distant from the national hospital required several resources and preparations. As stated by a chief medical officer of the VD hospital, "We needed more than a week to set up a distant clinical healthcare with over 100 technical staff [to support it]". Other national-level HFs could also establish their platforms with or without connecting them to the previous systems or lower-level HFs. This practice was characterized by a focus on professionals' health-related education (among HFs) and patients. The roles of other practitioners, such as the system providers, was simple. They were solely infrastructure supporters (e.g., telecommunications, networks, hardware, and software). The involvement of other practitioners was very limited, while HFs' IT and technical departments were responsible for most tasks. Although the practitioners' interacted with others, the flow of communication mainly occurred in a top-down manner: all tasks were operative within certain architectures and without any flexibility. In that sense, platformization practices were technically oriented. The platforms were set up by the IT and technical departments under the support of the third party (providers).

Up until 2013, the national-level HFs played a key role in establishing platforms. These platforms were stable. However, a new practitioner - the intervention of the government-was introduced (after 2013). This shook the platform stability. This can be considered a turning point as some new regulations and standards were introduced. This changed the platformization practice of eHealth. Those changes in the practices shifted the platformization practice, as described next.

\section{Phase 2. Platformization as Technical and Sociotechnical Practices}

The government (e.g., the Ministry of Information and Communications and the Ministry of Health) published several technical standards for HIS regarding IT applications and standardized processes for clinical healthcare, patient care, public health, and health administration in all HFs. However, the new development presented several challenges for current practices. First, the platforms had standards that had to be followed by harmonizing the practices, which influenced the practitioners. For example, platform owners had to redesign or reconfigure their systems, and the system providers had to update their infrastructure to meet the requirements. Second, all platforms needed to consider other organizational processes and standards. Third, the architecture had to be flexible and open-which contradicts the stability requirement before 2013 .

The current practices had to be changed to manage these requirements. The government, as a practitioner, participated in platform governance (e.g., in administrating and managing patient data) and functioned as a gatekeeper to ensure the support and compliance of new technical components of the platform. Figure 3 illustrates how the practices of platformization shifted. The differences between Figures 2 and 3 are the addition of new practitioners and the relationship between practitioners (indicated by bold arrows). 


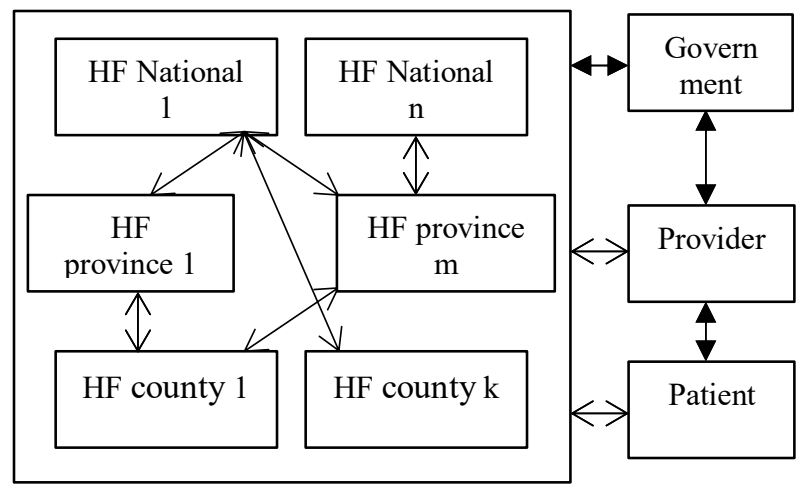

Figure 3. Sociotechnical approach toward the platformization practice of HIS in healthcare (20132017); key players: national-level $H F$ and the government

The joining of a new practitioner allowed more HFs to join the current platforms - or establish new ones, as the HFs had the freedom to do so provided the platform meets the government's requirements. In that sense, the platforms were developed in both bottom-up and topdown manners (compared to the earlier top-down approach). Subsequently, the government defined frameworks and set regulations that allowed different HIS or platforms to join. For example, this can be illustrated through the case of the MCIS platform. Vietnam has about 14,000 public HFs, each being relatively independent in using any HIS or platform to support their work. By 2017, there were appropriately $11 \mathrm{HIS} /$ platforms in a facility. The head of the electronic health administration stated, "Our aim is that every HF uses only one HIS as a platform to connect the central government to the municipalities in terms of data and management."

Another important perspective is communications between HFs. The interactions between the HFs were bidirectional. For example, an MCIS platform owned by an HF county can communicate (e.g., sharing and producing data) with the province and national-level HFs.

\section{Phase 3. Platformization as Technical, Sociotechnical, and Organizational Practices}

This section depicts the third phase, when the practice of platformization was again shifted and redefined. The freedom to establish personal platforms led to an increasing number of interconnected systems. Frankly, there were too many platforms. For example, there were about $11 \mathrm{MCIS}$ and platforms in an HF. Those systems were managed and operated by different parties. This led to inefficient operations, as stated by a nurse at an HF county: "Too many platforms eat out our resources and have negative impacts on healthcare staff.
For example, I have to enter the same data into different systems, as they are not connected."

Another challenge was that the platformization practices happened individually. Therefore, although all practitioners (e.g., HFs, government, system providers, and patients) participated in establishing platforms, each platform operated within its owners' circles and lacked a centralized coordinator that would oversee its development. The deputy head of the electronic health administration under the Ministry of Health said that "the openness of platforms opens up opportunities to increase the user base. However, it also creates chaos, as there are too many systems with different owners. They are all independent, and the interoperability between systems is poor."

Figure 4 illustrates the new platformization practice to tackle the emerging challenges from 2018-2020.

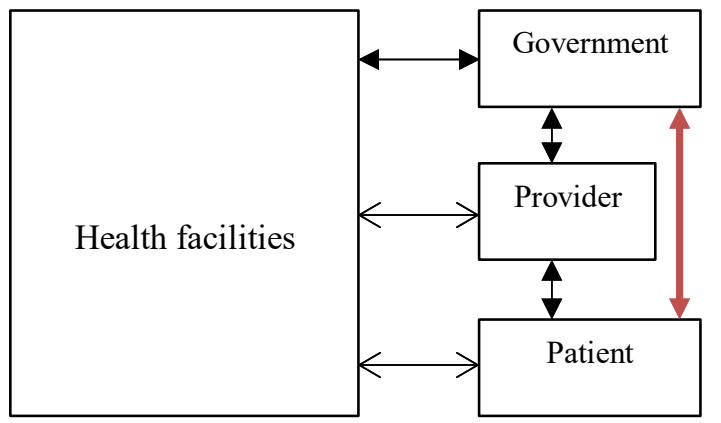

Figure 4. Organizational approach toward the platformization practice of HIS in healthcare (20182020); key player: government

Again, a new role was established. The government and its Electronic Health Administration agency functioned as the coordinator of the platformization practice. They helped to propose new legislation and policies to ease the facilitation of the process even further. This resulted in not every HF owning a platform anymore. Instead, the system providers and the government played a key role in developing platforms.

The platformization practice involved different practitioners, each contributing to its complementary components. The head of the electronic health administration articulated this development as follows: "From 2018, there was only one platform for MCIS, not 11 platforms as it was earlier from 2013 to 2017. This new platform was developed by the two biggest ICT companies and was applied for by about 11,000 HFs within the country. Furthermore, for telehealth, there were about 1,500 HFs (including foreign HFs such as Lao, South Korea, and Cambodia) with 42 medical specialties provided by the platforms by 2020." This story was complemented by the CEOs of two companies who developed the new platform. One stated that "the platform runs on IDC [data center], with the highest 
security and data protection. There are 23 different modules of the platform, and it is connected to all levels of the HFs." The other CEO then continued: "We have a strong cooperation with the government [and Electronic Health Administration agency] to consolidate all databases so that they become a platform, which is then managed by the government." In this sense, platform governance changed from complete openness in the previous phases to both control and openness (e.g., from the technological perspective), while platform infrastructure moved from stability to flexibility. The head of an HF in the province said: "The platform stores all the citizens' personal data. It needs to be controlled well. This means that each level of the HFs has different access rights to the platform. However, they also need to be open enough to give opportunities to new participating users to join in. Now, with the new platform, I can see the status of all HFs I manage in realtime. This was earlier impossible." The new practices allowed and supported the ecosystem development between the practitioners.

\section{Discussions}

\subsection{Site-Shifting Features in the Platformization of National eHealth Platforms}

The evolution of the three phases in the platformization practices of national eHealth platforms was presented earlier. Next, we outline their key features.

First, site-shifting in platformization is an inheritance process. This means that new practices are added to the old practices from previous phases, thereby complementing them. For example, adding a sociotechnical practice in the second phase did not influence the technical practice in the first phase. Instead, both practices existed simultaneously.

Second, the literature shows that technology has significant transformative power in the platforms. In fact, technology is considered a primary source of transformation [4]. However, in this study, while technology had its role, other practitioners played an even more critical role in the platformization of the national eHealth. For example, thanks to the government-established technical standards for HIS applications and standardized operational processes, platformization practices were significantly altered. The platform owners had to change their practices to adapt to the new situation, which was ruled by the new practitioner's (e.g., the government) requirements. This was described in Phase 2. Similarly, the role of practitioners in Phase 3 shifted when a new role was added to the list of practitioners. When the government became the coordinator, it increased interoperability and cooperation among all practitioners.

Third, site shifting in eHealth platformization is influenced by the practitioners co-creating their practices and systems. This indicates that the changes in the relationships or the ways of co-creation may significantly impact the platformization practices. For example, in Phase 3, the relationships between the coordinator and the system providers resulted in significant changes in their practices, as all HFs had to operate on a single platform.

Finally, the governing mechanisms influence the practitioners and their practices. The scope of governance affects external parties in processing data and sharing infrastructures with the partners. For example, in Phase 1, the platformization practices were controlled in that there was no possibility of involving or considering third parties in the systems. This resulted from the platform owner's governance policy.

\subsection{Approaches to Establishing National eHealth Platforms}

It can be argued that there are three approaches to establishing a national framework. First, the national platform can be established normatively in that the platform is installed in some selected HFs for a trial or pilot phase. During the trial process, the agency-incharge and its partners adjust and refine their functions as well as the requirements needed. The trial phase may last several years. Once it provides some benefits, regulations need to be changed or proposed as a foundation to implement the platform in a broader context, possibly to a national level. For example, the telehealth trial process lasted up to seven years before the government regulated the platform. This approach, thus, necessitates a long-term strategy and includes very high risks if the authority cannot issue regulations regarding the platform.

Second, the eHealth platform can be built on existing HIS. The authorities function as the coordinator who negotiates with the providers regarding technical and financial issues and their possibilities of establishing a platform on existing systems. For example, the MCIS system was established in this way. This approach is applicable in situations where there are already many HIS or digital capabilities. Yet, it must be acknowledged that it will be very challenging to establish a platform following this approach. For example, previous studies indicate that the biggest barriers to implementing a national healthcare information network in the US are either legislative or operational $[7,8]$.

Third, a national platform can be built from scratch. This starts by establishing regulations or legal 
frameworks and then piloting at the national level for all HFs. The MRP was created in this way. The advantage of this approach is its alignment with other IS or strategies. For example, the MRP was designed within the country's enterprise architectural framework [38]. In that sense, the platform can easily harmonize with other systems at different levels of administrative systems, from the central government (e.g., the Ministry of Health), local governments, and counties to the municipalities. For example, platforms can benefit from others regarding infrastructures (e.g., networks, hardware, and software), interoperability (e.g., among IS), and management (e.g., administrative levels, resources). Moreover, this top-down approach needs considerable resources and support from all partners but is far from an easy task $[39,40]$.

Each of the three types of approaches to establishing a national eHealth framework has certain challenges. For example, if we establish platforms based on existing HIS, legacy systems and processes will become an issue. This is because some HIS have been in operation long before the platform is established, so they have a lot of data and other legacies that are very difficult to integrate or mitigate. Despite these differences, all platformization practices share a common feature: their need for support from the government (administration) or political parties. If such support is not provided, the platform will likely fail. We simply cannot establish a national-level platform without government regulations.

Notably, as we discussed public eHealth platforms in Vietnam, economic factors did not appear in our study. Instead, they will most likely appear in a context where healthcare follows and is driven by market logic, as in the US [8].

\section{Conclusions}

National eHealth platforms are understudied in IS literature [10] since most of the literature focuses on technology-related issues and the private sector [3]. Therefore, we studied the platformization practices of national eHealth platforms to understand how an eHealth platform can be built.

Our first contribution was to illustrate the platformization practices of national eHealth platforms. Particularly, we illustrated three phases of these practices: technical, sociotechnical, and organizational practices. In each phase, the relationships between practitioners and material arrangements were identified. For example, in the organizational platformization practice of national eHealth platforms, the four practitioners were the HFs, the government, the system providers, and the patients. Material arrangements were, for example, the governance mechanisms for flexibility and openness in the technical infrastructure provided by two providers (two companies) and the control arrangement regarding patient data.

We also contributed to the literature by identifying key features of site-shifting in eHealth. Four features are as follows.

- Site-shifting is an inheritance process.

- Technology has its role, but other practitioners (e.g., government) play an even more critical role in platformization.

- Site-shifting is influenced by the practitioners co-creating their practices and systems.

- The governance mechanisms are important, as they influence the practitioners and their practices.

These features are valuable for practitioners, as they can be used as a reference when developing a platform. For example, while technology has its role, the importance of government is emphasized when wanting to develop a national eHealth platform.

We also recommended how national eHealth platforms should be created from our study. In particular, three approaches and their advantages and challenges are discussed. The normative method uses the bottom-up approach, building a platform from selected HFs. If the platform provides benefits, regulations need to be established as a foundation to extend the platform into a broader context. One challenge of this approach is that it needs a long-term strategy and support from the authority. The coordinative method uses the authority as a coordinator or mediator to establish a platform based on existing HIS or platforms. The biggest barriers to this approach are either legislative or operational. The controlled method uses the top-down approach by establishing legal frameworks and then piloting them at all levels of HFs. This approach requires considerable resources, commitments, and support from all involved stakeholders.

From the practice perspective, three practices can be used to build a national eHealth platform: technical, sociotechnical, and organizational practices. The technical practice indicates that the platform is technically oriented, while the sociotechnical practice indicates that the technical infrastructure is associated with processes and standards. The organizational practice indicates the authority involved in the process of establishing the platform (Table 1).

There are some limitations. First, we used three cases in a single developing country, with its governance and administrative methods and cultural contexts. This means that some issues (e.g., the market push/pull or economic factors) may play a very different role elsewhere. Nevertheless, we believe that the 
analysis of the three platforms still provides insights into how their development occurs. Second, we adopted an interpretive research approach. This is, as always, subject to subjective bias. However, we have coped with this by providing illustrative examples.

Acknowledgments. The last three authors' contributions are equal.

\section{References}

[1] Chen, L., A. Baird, and D. Straub, “An Analysis of the Evolving Intellectual Structure of Health Information Systems Research in the Information Systems Discipline", Journal of the Association for Information Systems 20(8), 2019.

[2] Davidson, E., A. Baird, and K. Prince, "Opening the envelope of health care information systems research", Information and Organization 28(3), 2018, pp. 140-151.

[3] Marques, I.C.P., and J.J.M. Ferreira, "Digital transformation in the area of health: systematic review of 45 years of evolution", Health and Technology 10(3), 2020, pp. $575-586$.

[4] Constantinides, P., O. Henfridsson, and G.G. Parker, "Introduction-Platforms and Infrastructures in the Digital Age", Information Systems Research 29(2), 2018, pp. 381400 .

[5] European Commission, "Full report on the results of the public consultation on the Regulatory environment for Platforms, Online Intermediaries and the Collaborative Economy", Shaping Europe's digital future - European Commission, 2016. https://ec.europa.eu/digital-singlemarket/en/news/full-report-results-public-consultationregulatory-environment-platforms-online-intermediaries

[6] Bonina, C., K. Koskinen, B. Eaton, and A. Gawer, "Digital platforms for development: Foundations and research agenda", Information Systems Journal n/a(n/a), 2021.

[7] Hill, J.W., A.W. Langvardt, and A.P. Massey, "Law, Information Technology, and Medical Errors: Toward a National Healthcare Information Network Approach to Improving Patient Care and Reducing Malpractice Costs", University of Illinois Journal of Law, Technology \& Policy 2007, 2007, pp. 159.

[8] Hill, J.W., and P. Powell, "The national healthcare crisis: Is eHealth a key solution?", Business Horizons 52(3), 2009, pp. 265-277.

[9] Paparova, D., and M. Aanestad, "Governing Innovation in E-Health Platform Ecosystems - Key Concepts and Future Directions", Selected Papers of the IRIS, Issue Nr 11 (2020), 2020.

[10] Vassilakopoulou, P., M. Grisot, T. Jensen, et al., "Building National eHealth Platforms: the Challenge of Inclusiveness", ICIS 2017 Proceedings, 2017.
[11] Schatzki, T.R., "Introduction: practice theory", In K.K. Cetina, T.R. Schatzki and E. von Savigny, eds., The Practice Turn in Contemporary Theory. Routledge, London and New York, 2001, 1-14.

[12] Schatzki, T.R., "Peripheral Vision: The Sites of Organizations", Organization Studies 26(3), 2005, pp. 465484.

[13] Selander, L., O. Henfridsson, and F. Svahn, "Capability Search and Redeem across Digital Ecosystems", Journal of Information Technology 28(3), 2013, pp. 183-197.

[14] Henfridsson, O., and B. Bygstad, "The Generative Mechanisms of Digital Infrastructure Evolution", MIS Quarterly 37(3), 2013, pp. 907-931.

[15] Rolland, K.H., L. Mathiassen, and A. Rai, "Managing Digital Platforms in User Organizations: The Interactions Between Digital Options and Digital Debt", Information Systems Research 29(2), 2018, pp. 419-443.

[16] Gawer, A., "Bridging differing perspectives on technological platforms: Toward an integrative framework", Research Policy 43(7), 2014, pp. 1239-1249.

[17] Dang, D., and T. Vartiainen, "Digital strategy patterns in information systems research", PACIS 2019 Proceedings, 2019.

[18] Dang, D., and T. Vartiainen, "Changing Patterns in the Process of Digital Transformation Initiative in Established Firms: The Case of an Energy Sector Company", PACIS 2020 Proceedings, 2020.

[19] Yoo, Y., O. Henfridsson, and K. Lyytinen, "Research Commentary - The New Organizing Logic of Digital Innovation: An Agenda for Information Systems Research", Information Systems Research 21(4), 2010, pp. 724-735.

[20] de Reuver, M., C. Sørensen, and R.C. Basole, "The Digital Platform: A Research Agenda", Journal of Information Technology 33(2), 2018, pp. 124-135.

[21] Sørensen, C., M. de Reuver, and R.C. Basole, "Mobile platforms and ecosystems", Journal of Information Technology 30(3), 2015, pp. 195-197.

[22] Nieborg, D.B., and T. Poell, "The platformization of cultural production: Theorizing the contingent cultural commodity", New Media \& Society 20(11), 2018, pp. 42754292.

[23] Wynn, E., and H.V. Hult, "Platforms and the Public Sphere”, AMCIS 2020 Proceedings, 2020.

[23] Dang, D., and S. Pekkola, "Institutional Perspectives on the Process of Enterprise Architecture Adoption", Information Systems Frontiers 22(6), 2020, pp. 1433-1445.

[24] Kraus, S., F. Schiavone, A. Pluzhnikova, and A.C. Invernizzi, "Digital transformation in healthcare: Analyzing the current state-of-research", Journal of Business Research 123, 2021, pp. 557-567.

[25] Bush, J., and J. Fox, "Bringing the Power of Platforms to Health Care", Harvard Business Review, 2016. 
https://hbr.org/2016/11/bringing-the-power-of-platforms-tohealth-care

[26] Stroetmann, K., J. Artmann, and V. Stroetmann, European countries on their journey towards national eHealth infrastructures, 2011.

[27] Aanestad, M., and T.B. Jensen, "Building nation-wide information infrastructures in healthcare through modular implementation strategies", The Journal of Strategic Information Systems 20(2), 2011, pp. 161-176.

[27] Dang, D., T. Vartiainen, and S. Pekkola, "Patterns of enterprise architecture adoption in the public sector: A resource-based perspective", Proceedings of the 27th European Conference on Information Systems (ECIS), (2019), 17.

[28] Lanamäki, A., K. Väyrynen, S. Laari-Salmela, and M. Kinnula, "Examining relational digital transformation through the unfolding of local practices of the Finnish taxi industry", The Journal of Strategic Information Systems 29(3), 2020, pp. 101622.

[29] Huang, J., S. Newell, J. Huang, and S.-L. Pan, "Siteshifting as the source of ambidexterity: Empirical insights from the field of ticketing", The Journal of Strategic Information Systems 23(1), 2014, pp. 29-44.

[30] Chanias, S., M.D. Myers, and T. Hess, "Digital transformation strategy making in pre-digital organizations: The case of a financial services provider", The Journal of Strategic Information Systems 28(1), 2019, pp. 17-33.

[31] Schatzki, T., "Keeping Track of Large Phenomena", Geographische Zeitschrift 104(1), 2016, pp. 4-24.

[32] Vaara, E., and R. Whittington, "Strategy-as-Practice: Taking Social Practices Seriously", Academy of Management Annals 6(1), 2012, pp. 285-336.

[33] Kouamé, S., and A. Langley, "Relating microprocesses to macro-outcomes in qualitative strategy process and practice research", Strategic Management Journal 39(3), 2018, pp. 559-581.

[34] Nicolini, D., "Practice as the Site of Knowing: Insights from the Field of Telemedicine", Organization Science 22(3), 2011, pp. 602-620.

[35] Klein, H., and M. Myers, "A Set of Principles for Conducting and Evaluating Interpretive Field Studies in Information Systems", Management Information Systems Quarterly 23(1), 1999.

[36] Walsham, G., "Interpretive case studies in IS research: nature and method", European Journal of Information Systems 4(2), 1995, pp. 74-81.

[37] Eisenhardt, K.M., "Building Theories from Case Study Research", The Academy of Management Review 14(4), 1989, pp. 532-550.

[38] Dang, D., "Institutional Logics and Their Influence on Enterprise Architecture Adoption", Journal of Computer Information Systems 0(0), 2019, pp. 1-11.

[39] Lemmetti, J., and S. Pekkola, "Understanding Enterprise Architecture: Perceptions by the Finnish Public Sector", Electronic Government, Springer (2012), 162-173.

[40] Dang, D.D., and S. Pekkola, "Problems of Enterprise Architecture Adoption in the Public Sector: Root Causes and Some Solutions”, In L. Rusu and G. Viscusi, eds., Information Technology Governance in Public Organizations: Theory and Practice. Springer International Publishing, Cham, 2017, 177-198. 